\title{
A DEMOCRACIA PARTICIPATIVA À LUZ DA CONSTITUIÇÃO DE 1988: PARA UMA APROXIMAÇÃO ENTRE O DIREITO DE LIBERDADE, EM PHILIP PETIT, E O RETORNO À ÁGORA, EM ZIGMUND BAUMAN
}

Elda Coelho de Azevedo Bussinguer ${ }^{1}$ Isabela de Deus Cordeiro ${ }^{2}$

\section{Resumo}

As manifestações de 2013 e a constatação de um estado generalizado de impotência coletiva, ao tempo em que sinalizam certa contradição, encampam também uma relação de complementariedade que parece ser a marca da complexidade das sociedades modernas. O presente artigo analisa a alternativa de retorno à ágora, espaço nem público nem privado, antes público e privado, de construção de soluções coletivas em face de problemas individuais, tratado por Zigmund Bauman, e as exigências constantes da teoria de Philip Petit acerca da liberdade, vista como condição de ser considerado responsável, visando propor um horizonte mais promissor a ser trilhado pela sociedade atual. Em face da natureza dos objetivos propostos e dos autores utilizados no processo analítico a abordagem dialética foi aplicada. Conjugando os dois aspectos mencionados, vislumbra-se uma perspectiva constitucional e sociologicamente rica, qual seja, a que possibilita aos indivíduos, no âmbito do controle discursivo e no exercício do ideal de liberdade política, que efetivamente assumam a condição de protagonistas, dialogando permanentemente em torno do projeto político cujas bases estão fixadas na Carta Constitucional.

Palavras-Chave: Democracia; Liberdade Política; Responsabilidade, Participação Popular.

\section{INTRODUÇÃO}

As manifestações de 2013 aliadas a um estado generalizado de impotência coletiva e à descrença em relação a melhores rumos que possam ser trilhados pela sociedade atual, ao tempo em que sinalizam certa contradição, encampam também uma relação de complementariedade que parecem ser a marca da complexidade das sociedades modernas.

A compreensão desse estado de coisas pode representar alternativa de dias futuros mais promissores que aqueles que ora estão sendo vivenciados. Nessa esteira, o presente artigo tem por objetivo reafirmar a proposta de

\footnotetext{
${ }^{1}$ Doutora em Bioética pela UnB. Professora e Coordenadora do Programa de Pós-Graduação em Direitos e Garantias Fundamentais da FDV. Coordenadora do Biogepe - Grupo de Estudos, Pesquisa e Extensão Políticas Públicas, Direito à Saúde e Bioética. E-mail: elda.cab@gmail.com

${ }^{2}$ Coordenadora do Centro de Apoio Operacional de Meio Ambiente e Urbanismo do Ministério Público do Estado do Espírito Santo. Mestranda em Direitos e Garantias Fundamentais pela Faculdade de Direito de Vitória. E-mail: isabeladedeus@hotmail.com
} 
Zigmund Bauman, de retorno a ágora, ao tempo em que propõe ande, lado a lado, com ideal de liberdade política de Philip Petit, sendo, pois, condição a que os indivíduos efetivamente ocupem esse espaço.

A compreensão da largura e da medida do que venha a representar esse direito de liberdade, ou a sua leitura, atualizada e dialogada com a sociedade, faz-se necessária a fim de que o projeto político constitucional ganhe legitimidade social, correspondendo àquilo que uma sociedade pós-moderna, fragmentada, instantânea e plural almeja.

Nesse viés, importa reconhecer que se o traço distintivo da formação da Constituição reside no fato de ela reunir grupos e forças distintas em uma dada sociedade política, esse traço não deixa de ser uma realidade após a sua promulgação. O reconhecimento de uma Constituição como instrumento voltado à formação e manutenção de uma unidade política e a criação e estabilização do ordenamento jurídico tem por pressuposto uma perspectiva histórica que se estabeleça recíproca e permanentemente e dá origem a um sistema interpretativo eminentemente aberto (HESSE, 2009, p. 4) ${ }^{3}$.

A justificação, contudo, do caráter vinculante apenas sob a perspectiva normativa não parece suficiente à afirmação da autoridade constitucional, parecendo que o que de fato o justifica não se resume à norma em si, senão também ao seu conteúdo e correspondência com os anseios sociais.

Ao reclamo permanente de um conteúdo que traduza as aspirações sociais, Ackerman (2006, p. 43), propõe um retorno às bases republicanistas de interpretação da Constituição americana, e defende a necessidade de que o espírito da democracia dualista se redescubra na Constituição a partir de uma linguagem viva para um governo autônomo.

Com razão. Se o espaço social pós-moderno é marcadamente fragmentado, tensionado entre forças políticas e ideológicas distintas e poderes pulverizados socialmente, todos refletindo sua complexidade, ele nem por isso deixa de reivindicar, de modo permanente, uma práxis estatal que reconheça a necessidade de buscar naquele e para ele (espaço social), sua força motriz e legitimidade.

Significa dizer que à justificação simbólica encontrada no preâmbulo constitucional, que respalda, ao menos normativamente, a força constitucional, devem se seguir espaços jurídicos que diuturnamente a alimentem, através de canais que possibilitem uma maior participação popular nos processos de tomada de decisão política.

Constata-se, apesar disso, a incapacidade da sociedade moderna atual em formar, manter e alimentar uma agenda pública que seja capaz de reunir seus cidadãos em torno do projeto político que se deseja, e isso independe do que venha a configurar o seu conteúdo. Talvez seja possível afirmar que o facebook seja o espaço

\footnotetext{
${ }^{3}$ Sobreleva destacar que a circunstância da Constituição dar origem a um sistema aberto não significa seja ele ilimitado, ao contrário, segundo Hesse (2009, p. 10) “...abertura e vinculação, são pressupostos do cumprimento das tarefas da Constituição." No entanto, a vinculação será restrita à estrutura do Estado e aos procedimentos que se desenvolvam em seu interior.
} 
mais público de que se tenha notícia.

A ausência desse ideal transcendental que seja capaz de reunir os indivíduos em torno de objetivos que lhe digam respeito e das lutas pelas quais efetivamente acreditem que valham a pena, culminou com a circunstância de serem analogamente comparados a mônadas. Na qualidade de átomos, ilhas isoladas, o panóptico de Benthan foi substituído pelo sinóptico, ou seja, o desaparecimento do público através de um contínuo processo de incorporação pelo privado.

O zelo pelo aperfeiçoamento e aprimoramento dos espaços de participação popular devem ensejar a sua valorização como pressuposto necessário ao avanço real do ideal democrático das sociedades modernas, a exemplo, das participações populares garantidas quando da elaboração de planos que orientem a implementação de políticas públicas, dos plebiscitos, referendos e das audiências públicas.

No entanto, isso também não basta. Em uma sociedade globalizada de ideologia cooptada e pautada pelo mercado, qual o significado da afirmação das bases ou espaços de construção democrática para a concretização do projeto político constitucional? Por outro lado, ainda que se afirme a importância de uma construção política mais democrática, quais são seus pressupostos? No que os pressupostos do direito de liberdade traçados por Philip Petit tocam a construção do projeto político democrático de retorno à ágora de Bauman?

É possível ensaiar, desde já, uma resposta afirmativa, ou seja, afirmando a importância desses espaços de construção democrática na qualidade de mecanismos de concretização da democracia participativa e consequentemente de exercício do poder político constitucional, reconhecidos pela Carta Constitucional de 1988, ainda quando não cumpram na sua totalidade, aquilo que deles se espera.

Mas isso longe está de representar um nível satisfatório com a democracia que hoje se experimenta. É possível esperar mais desses espaços e isso pressupõe uma concepção específica de liberdade política que seja manifestada e vivenciada por meio do retorno à ágora.

Eis o que se deseja com o presente artigo: contribuir para a identificação de horizontes mais promissores que aqueles que ora podem ser vislumbrados a partir da democracia restritamente representativa, justificando a necessidade do retorno à ágora: espaços nem públicos nem privados, antes públicos e privados, de construção de soluções coletivas em face de problemas individuais, mas que, no atual estágio da sociedade complexa, exige níveis de liberdade bem peculiares.

\section{A POLITICA COMO APROXIMAÇÃO ENTRE DEMOCRACIA E FILOSOFIA NA PÓLIS GREGA}

A compreensão da democracia grega pode apresentar, em alguma medida, algum interesse para a 
democracia atual das sociedades, mesmo as periféricas. Situando-se como berço da democracia, nela se pode encontrar a base, o gérmen e as potencialidades de um ideal político que, ainda que contextualizado historicamente em dada sociedade, contribui para as perspectivas de concepção da democracia moderna.

Essa contribuição está intimamente relacionada ao fato de que, ainda quando não relacionados intrinsecamente, os fatos sociais que ocorrem em dada sociedade são capazes de compor fenômenos que, somados às mesmas precondições sociais, históricas e pessoais dão origem a certas universalidades, a que Castoriadis (2002, p. 281) denomina de "universalidades potenciais", sugerindo que sua criação seja decorrente da imaginação criadora dos indivíduos que a compõem.

Essas universalidades potenciais são responsáveis por traduzir certa significação ou conteúdo que, de outro modo, seriam desconectados e não compreensivos, mas que reunidos em processos semelhantes elucidam e iniciam processos de elucidação (CASTORIADIS, 2002, p. 282). Tais processos caminham, inclusive, para além da sociedade nas quais essas universalidades se originam, quando correspondem aos mesmos vínculos sociais genealógicos.

Nessa linha, a atitude reflexiva é uma singularidade eminentemente greco-ocidental ou europeia, ou seja, proveniente de processos elucidativos que, de modo semelhante, permearam as sociedades respectivas. Em face delas e da tradição a que deram origem, a política caminha pari passu com a filosofia, a reclamar permanentemente uma argumentação racional que, por sua vez, demanda, a todo momento, atitudes de julgamento e escolha orientando os sentidos de criação da política e da filosofia.

Castoriadis (2002, p. 299), afirmando que a política consiste na "atividade coletiva cujo objetivo é a instituição da sociedade", aponta que "a criação da democracia e da filosofia, e de sua ligação, encontra uma precondição essencial na concepção grega do mundo e da vida humana, no núcleo do imaginário grego" (CASTORIADIS, 2002, p. 300).

Mas existem premissas que orientaram a possibilidade da democracia e da filosofia e que justificaram os movimentos de autonomia e consequentemente de deliberação política, correspondendo ao reconhecimento de que é possível trazer algum nível de ordenação ao caos do universo; não existe uma ordenação perfeita que oriente a vida em geral e que a ação política é o mecanismo por meio do qual essa ordenação pode acontecer.

Tais condições atuam conjuntamente e foram pioneiramente apropriados pela cultura grega, de modo que romperam a ontologia unitária do mundo que apontava para uma total heteronomia (CASTORIADIS, 2002, p.302).

Contudo, Habermas (2005, p. 114) aponta como um dos grandes desafios que orientam a modernidade, inclusive, em função da crise em relação à proposta do Estado do bem-estar social, o fato de que, ao incremento material e ao processo de imediação do Estado por meio de regras estabelecidos diante dos conflitos verificados a partir da exploração das classes, seguiu-se uma concomitante burocratização do poder e substituição vol.10, nº. 01, Rio de Janeiro, 2017.pp. 127-148 
da democracia de base, pelos partidos políticos.

Tal processo é contrário à proposta grega de que é o coletivo dos cidadãos que compõe o absoluto soberano que deve exercer a autonomia, estabelecendo suas próprias leis. Esse coletivo, não obstante, guarde as peculiaridades de seu contexto histórico e cultural, será aquele ao qual a lei atribui a condição de participação ativa nos negócios públicos (CASTORIADIS, 2002, p. 304). Mas isso tem um significado peculiar na cultura grega, qual seja, o de exigir a participação efetiva dos cidadãos, e mais, o estabelecimento de regras formais que ativamente encorajem à participação na construção coletiva.

Não por outro motivo, Castoriadis (2002, p. 306) afirma seja a representação um princípio estranho à democracia:

Benjamin Constant não glorificou as eleições nem a 'representação enquanto tais, mas as defendeu enquanto males menores, supondo que a democracia se tornara impossível nos países modernos em razão de suas dimensões e que as pessoas não mais estavam interessadas nos assuntos públicos. Seja qual for o valor desses argumentos, eles se baseiam no reconhecimento explícito do fato de que a representação é um princípio estranho à democracia. E isto dificilmente admite discussão. Uma vez que haja 'representantes' permanentes, a autoridade, atividade e iniciativa políticas são retiradas do corpo de cidadãos e transferida para o corpo restrito dos 'representantes' - que as utilizam de modo a consolidar a sua posição e a criar condições propícias a influenciar, de muitos modos, o resultado das próximas 'eleições'.

Por isso Habermas $(2005,106)$, aponta para a circunstância de que, em parte a crise do Estado do bemestar social, está relacionada ao fato de que à acumulação material seguiu-se um déficit democrático, fruto de uma pauperização política, e que pressupõe, para a sua sobrevivência, a ampliação dos processos de participação democrática.

É, pois, na participação coletiva que se dá ensejo à verdadeira democracia, fazendo surgir o que Castoriadis (2002, p. 311) denomina de espaço público, in verbis: "a participação geral na política implica a criação, pela primeira vez na história, de um espaço público". E continua: "a emergência de um espaço público significa que se criou um domínio público que 'pertence a todos'. O 'público’ deixa de ser um espaço 'privado'. As decisões relativas aos assuntos comuns devem ser tomadas pela comunidade".

Isso é bem desenvolvido por Bauman quando propõe que a verdadeira política se dê mediante o retorno à ágora.

\section{A DEMOCRACIA PARTICIPATIVA COMO ESPAÇOS DE RETORNO A ÁGORA}

A necessidade de retorno a espaços públicos que traduzam demandas individuais em coletivas é bem destacada por Zigmund Bauman (1999, p. 9) que chama a atenção para a circunstância de que o aparente aumento da liberdade foi seguido de um estado de impotência em relação às questões que dizem respeito a todos. 
Fruto de um sistema de crenças que, independentemente de obedecerem a uma lógica, foram incorporadas e moldam nossas convicções, o olhar sobre a vida, tal como o habitus de Pierre Bourdieu (1999, p. 9), a "satisfação com os níveis de liberdade experimentado anda lado a lado com a desesperança em torno das possibilidades de mudança do mundo existente".

A compreensão, contudo, desse estado de coisas, pode representar a identificação de alternativa capaz de assegurar um verdadeiro estado de liberdade, não o que se verifica hoje, responsável por uma impotência coletiva, ou oriundo da destruição das pontes entre a vida pública e privada.

A apatia coletiva instalada sinaliza uma permanente recusa de alternativas à ideologia do liberalismo e cria uma espécie de política que trabalha na manutenção das coisas, no que acomoda e se alimenta da ditadura do mercado e da omissão estatal. Este último, na grande maioria das vezes, senão sempre, coloca-se a serviço do primeiro, e contribui, através de uma postura omissiva, para a verificação de uma cidadania cujas preocupações giram, no máximo, em torno dos níveis de consumo.

Compreender esse fenômeno talvez represente alternativa à adoção de novas posturas que possibilitem a resolução de um grande problema que parece ter-se transformado na tônica do momento: o processo generalizado de exacerbação do sofrimento humano relacionado a uma somente aparente liberdade, fruto da má política e do que resulta a ausência de expectativas.

\section{A fragilidade das totalidades e o fracasso do ideal de liberdade prometido pela modernidade}

As totalidades que sempre orientaram e nutriram o caráter imortal das vidas humanas, especialmente simbolizadas por meio do Estado-nação e da família, já na pós modernidade, passaram à condição de laços frágeis e inseguros. Sendo responsáveis por conferir certo sentido transcendente e durável à natureza transitória e vulnerável da existência humana, representavam espaços capazes de, minimizando os níveis de insegurança e incerteza, dar sentido e direção à vida mortal dos indivíduos que, de outra sorte, nutririam um aspecto tão efêmero, quanto irrelevante.

As nações, no advento da modernidade, representaram espaços propícios à experiência supra individual, à reprodução do ideal de eternidade buscado pelo homem, além de parecerem acessíveis a todos os indivíduos, como um grande espaço de pertença democraticamente reconhecido (Bauman, 1999, p. 43). Também a família, de forma ainda mais dialético, promoveu importante interlocução entre a mortalidade e a imortalidade, o fazer e o sofrer, o determinar e o ser determinado, ao criar e o ser criado.

As duas totalidades conformavam a conjugação da durabilidade na transitoriedade, ou seja, a possibilidade da existência para além da morte. Algo como dizer: o meu "eu" pode morrer, mas minha família e 
minha nação permanecem.

Mas se tais totalidades traduziam espaços seguros e garantias perenes da individualidade humana, na evolução do estágio atual passaram a configurar espaços tão inseguros quanto aqueles que outrora fomentaram suas criações.

Acerca da família Bauman (1999, p.49), de modo cristalino, constata:

A família, hoje em dia, não se encontra em melhor estado, ela parece tudo, menos um paraíso seguro e duradouro onde se possa lançar a âncora da própria existência vulnerável e sabidamente transitória. Tão fácil de terminar quanto de começar e tão fácil de desmantelar quanto de montar.Já não se pode esperar que a família dure mais do que aqueles que a criam no mundo. A ponte para a eternidade é tão frágil e exorável quanto as pessoas que a utilizam - talvez ainda mais efêmera que a passagem delas.

Não foi diferente com o Estado nação que se converteu em um território sem poder. À concepção de estado como o conjunto de pessoas, territorialmente localizadas e unidas por laços culturais semelhantes, tradutor de significativa parcela do poder político, seguiu-se sua minimização, fruto da associação do poder político ao poder econômico, e seu deslocamento para o ciberespaço, operado de modo transfronteiriço e posto a serviço do mercado. A estrutura básica da economia global restou cada vez mais dissociada e agora ultrapassa a estrutura política do mundo (BAUMAN,1999, p. 47).

Nogueira (2013, p. 42) acerca do poder no Estado brasileiro declara: "os centros de poder entraram em crise, perderam transparência e força. O poder não está no Palácio do Planalto ou em algum outro palácio. Os partidos pesam pouco na organização dos consensos sociais". O que restou ao indivíduo, localizado territorialmente e à espera de quem possa tornar mais leve o seu fardo existencial, foi, então, o seu completo abandono.

Essas alterações sofridas especialmente nas totalidades mencionadas impactaram sobremaneira a agenda pública antes orientada pelo bem comum ou pelo ideal do interesse público. Assim, se em determinado momento da evolução histórica das sociedades pôde-se assistir a espaços temporais nos quais a agenda pública, em certa medida, apropriou-se da agenda privada, atualmente, constata-se diametralmente o oposto.

Assiste-se, permanentemente, a um processo de ampliação e apropriação privada dos interesses antes públicos, situação que contribui para a falsa sensação de liberdade que se tem. Bauman (1999, p. 48) afirma que "em algum ponto do trajeto para o livre comércio global, a função doadora de sentido da comunidade nacional se perdeu e os indivíduos foram abandonados para lamber suas próprias feridas e exorcizar seus medos em solidão e reclusão."

Isso deveu-se, em grande medida, ao processo de pauperização política ou déficit democrático, atribuído por Habermas, interpretado por Danner (2001, p. 494), vez que, mesmo considerando que o Estado do bemestar social em certa medida foi capaz de responder aos desejos de acumulação material dos cidadãos, mais adiante assistiu-se a um processo em que essa ampliação pareceu não mais coincidir com os anseios sociais, 
criando-se uma espécie de fosse, de separação entre as ações estatais e os anseios sociais. É dizer: ao processo de estabilização sistêmica que, inicialmente, foi alcançado pelo Estado do bem-estar social, deu-se um passo na direção da independência de suas ações frente à legitimidade democrática.

No caso da sociedade brasileira, isso assumiu um contorno ainda pior. Nogueira (2013, p. 41) aponta o acirramento da crise política ao longo do tempo, situação que culminou com as manifestações sociais nas ruas, e em todo o território nacional, em 2013 e 2014. Segundo ele houve contribuição considerável dos governos para o esvaziamento do público na medida em que aos projetos de hegemonia, antes orientadores das agendas políticas, seguiram-se projetos de poder. Exibindo falhas graves e desempenho medíocre, "não se preocuparam em transferir maior politicidade à sociedade civil, que cresceu em dimensão e ativismo sem conseguir contornar a fragmentação". Ao crescente estado de miséria e abandono da sociedade, seguiu-se seu distanciamento do Estado.

Os indivíduos, portanto, tornaram-se mônadas ou ilhas e sentiram que as redes que os ligavam a outras pessoas e que compunham as totalidades ora mencionadas vem sendo, paulatinamente demolidas. Bauman (1999, p. 73) reconhece que essas redes, a todo o momento, estão sendo "decompostas, rasgadas ou totalmente dilaceradas a toque de caixa ou sem prévio aviso, com pouco ou nenhum esforço".

Esse quadro é nada menos que uma contradição em relação àquilo que prometia a modernidade. Um breve retorno histórico é capaz de trazer à memória que as promessas modernas giravam em torno da elevação dos níveis de liberdade experimentados pelos cidadãos que compunham as sociedades.

Mas não se tratava de uma liberdade qualquer, senão aquela que fosse ativa, de fazer coisas e refazê-las para melhor responderem às necessidades da existência humana. Bauman (1999, p. 77) assinala que a liberdade, naquele tempo, "tinha como elemento primordial a capacidade de dar às coisas uma forma tal que os membros da espécie não fossem mais impedidos de agir de acordo com o mais humano dos seus dons naturais: o poder de fazer juízos racionais e se portar segundo os preceitos da razão".

Assiste-se, contudo, a um processo paulatino e não reflexivo de retração dos espaços públicos de tradução coletiva de demandas individuais; a diminuição estatal e sua consequente desregulamentação das questões socialmente relevantes, assim como o desestímulo aos espaços em que a necessidade dessa regulamentação pudesse ser estabelecida, têm sido responsáveis pela descrença, senão frustração, em torno da liberdade experimentada.

E isso tem uma razão de ser: a desregulamentação estatal ou a própria retração social dos espaços antes tido como de conjugação pública não tem o condão de sinalizar a simples inexistência ou ausência de regulamentação, ao contrário, significam a sua apropriação por parte de instituições ou agências que só tem a ganhar com o aumento da insegurança e da ausência de garantias, quais sejam, o mercado e o consumo. Por isso a constatação de Bauman (1999, p. 80): 
Desregulamentar' significa diminuir o papel regulador do Estado, não necessariamente o declínio da regulamentação, quanto mais o seu fim. O recuo ou autolimitação do Estado tem como efeito mais destacado uma maior exposição dos optantes tanto ao impacto coercivo (agendador) como doutrinador (codificador) de forças essencialmente não políticas, primordialmente aquelas associadas aos mercados financeiro e de consumo.

O mundo passou a ser identificado como um grande objeto de consumo e as relações que usualmente uniam os indivíduos passaram à condição de meras representações dos níveis de consumo estimulados por meio de processos de indução daqueles a cumprir, no máximo, a expectativa de consumidores que deles se espera, e, nada mais além disso.

Habermas (2005, p. 107) chama a atenção para o papel do Estado no alimentar o processo de politização x despolitização das massas, que marca do déficit democrático atualmente, atribuindo-o à eliminação da participação política e à crescente atribuição dela aos partidos políticos e à tecnocracia. Esse aspecto é particularmente importante pois a partir dele constata-se que a suposta estabilização sistêmica pretendida pelo Estado do bem-estar social e partir da qual, num primeiro momento, representou o equilíbrio entre o capital e o trabalho, já num segundo passou a representar o fundamento das críticas levantadas contra esse modelo, que, consoante Habermas, apresenta um viés psicossocial.

Também Nogueira (2013, p. 44) constata que a crise do governo representativo e também do sistema político, sob a influência do mercado, seduziu jovens brasileiros para o consumo e despolitização, ou ainda, para a busca de novas formas de militância e politicidade. É possível, pois, pensar algum caminho alternativo?

\section{A ideologia em crise da modernidade atual: para um retorno à ágora}

A ideologia que ora está em vigor é bem sub-reptícia, subliminar, incutida paulatinamente nos cidadãos que sequer percebem que estão na condição de escravos, desenvolvida e alimentada a partir do que Bourdieu (1989, p. 45) nomina de habitus, ou seja, "um sistema de disposições duráveis inculcadas desde a mais tenra infância que pré-molda possibilidades e impossibilidades, oportunidades e proibições, liberdades e limites de acordo com as condições objetivas."

Nesse viés, Bourdieu (1989, p. 15) nos informa que "o que faz o poder das palavras e das palavras de ordem, poder de manter a ordem, ou de a subverter, é a crença na legitimidade das palavras e daquele que as pronuncia, crença cuja produção não é da competência das palavras. ” Com efeito, o modo como a ideologia neoliberal vem se impondo aparentemente de modo quase que natural, por meio de um disfarce é constatado por Bauman (1999, pp. 4-5) que afirma:

A integração e reprodução da 'ordem global' toma mais uma vez o disfarce de um processo espontâneo e impelido por si mesmo. A grande novidade da modernidade foi apresentar a criação, preservação e continuidade da 'ordem' como uma tarefa, um propósito dificilmente atingível sem uma ação humana decidida, concertada e consciente de sua meta.

Reconhece o autor que a produção da ordem deixou de ser vista como algo concertado, assumindo a vol.10, nº. 01, Rio de Janeiro, 2017.pp. 127-148 
condição de uma empreitada suspeita por interferir naquilo que foi apropriado pela 'invisible hand' e, de certo modo, atemorizou os indivíduos que preferiram assumir posturas passivas de aceitação a contar com a possibilidade de realidades piores do que as que se apresentam.

É essa ideologia que acaba por estabelecer uma crença generalizada de que não há alternativa para o que está posto, ou de que as alternativas que possam ser cogitadas podem representar situações ainda mais graves que não justificam quaisquer investimentos ou processos reflexivos e de transformação social. Afinal, o que, supostamente, poderia ser pior que a insegurança de algo que não se conhece?

A ausência de uma análise crítica desse processo chega a situações que beiram a irracionalidade, especialmente quando confrontadas com a suposta liberdade experimentada. Nesse estágio, a falta de liberdade assume a condição de opressão ou, no mínimo, de dominação, sendo os agentes forçados a agir contra a vontade, sofrendo por não serem capazes de se portar como desejam ou como o fariam por conta própria. E mais, sob a ignorância de não se reconhecerem como fazendo parte de um jogo de forças e cujo o resultado da partida já se estabelece desde o seu início.

Contudo, uma análise mais atenta e detida pode ser capaz de levar a que os indivíduos percebam que a liberdade prometida, se é que se apresenta como uma realidade, ao menos sob o aspecto normativo, o é apenas aparentemente, afigurando-se como verdadeira antiliberdade.

No caso da sociedade brasileira, as manifestações nas ruas que se seguiram durante os anos de 2013 e 2014 evidenciam o descontentamento e insatisfação a que chegou sociedade com os políticos e com a própria política de um modo geral, podendo-se falar em uma crise sistêmica.

A sociedade parece ter despertado para sua completa antiliberdade, já que as vozes reverberaram a crise estatal em prover e dar respostas às demandas coletivas. Nogueira (2013, p. 45) exemplifica o que as vozes pareciam denunciar: "as falhas do sistema educacional, do sistema de saúde pública, dos transportes, da infraestrutura, a ineficiência dos governos e dos sistemas políticos, suas taxas absurdas de corrupção dentre outros.

Essa escravidão, contudo, assume a condição de liberdade, mas no íntimo é uma ilusão protegida de qualquer mecanismo de desmascaramento que se vale de processos ordinários de agenciamento e codificação, tanto nos aspectos legislativo, educacional quanto moral.

A descoberta, assim, pressupõe a constatação de que ao espaço vazio, deliberado ou levianamente deixado pelo público e verificado especialmente nos processos de agenciamento e codificação, responsáveis, respectivamente, pelas alternativas postas à disposição dos indivíduos e pelo código de escolhas que os orienta, se seguiu uma apropriação indevida, inadequada e premeditada do privado.

A alternativa ao retorno do público passa, necessariamente, pelo processo de rompimento com os pressupostos da ideologia posta e pelo resgate da autonomia social, situação que permitirá a retomada dos espaços de discussão pública, a exemplo dos espaços de participação democrática. Espaços esses que permitam uma vol.10, nº. 01, Rio de Janeiro, 2017.pp. 127-148 
atitude reflexiva, crítica e propositiva por parte da sociedade em relação às instituições e aos próprios rumos que vem sendo por ela trilhados.

Mas para que isso se possa verificar é fundamental a realização da autonomia em toda a sua amplitude, abandonando-se a suposta segurança que, de modo tão intenso parece aprisionar os indivíduos, lançando-se os cidadãos à condição de sujeitos ativos de participação nas questões públicas.

Nesse viés, se a autonomia pressupõe o andar de mãos dadas com o olhar crítico e reflexivo sobre as instituições, também passa por um lançar atenção sobre a tradição, o estar consciente da historicidade social que possibilite um aprendizado em torno da autêntica política.

O ápice dessa autonomia? É o que se pode esperar da essência da democracia, do seu mais alto nível, da condição de povo ativo que se propõe. Sobre isso, Castoriadis (1997, p. 4-5) arremata:

Atividade explícita e lúcida que diz respeito à instauração das instituições desejáveis e da democracia como regime da máxima auto instituição possível, explíita e lúcida, das instituições sociais que dependem da atividade coletiva explícita.

É praticamente desnecessário acrescentar que essa auto instituição é um movimento que não pára, que não visa a uma 'sociedade perfeita', mas antes, a uma sociedade livre e o mais justa possível. É a esse movimento que chamo projeto de uma sociedade autônoma, o qual, se quiser vingar, tem que criar uma sociedade democrática.

Eis o restabelecimento das pontes que antes ligavam a vida pública à privada (BAUMAN, 1999, p. 1011), espaços destinados a "procurar coletivamente alavancas controladas e poderosas o bastante para tirar os indivíduos da miséria sofrida em particular; espaço em que as ideias podem nascer e tomar a forma como bem público', 'sociedade justa' ou 'valores partilhados'”.

A chave para isso pressupõe a igualdade de valor na participação de cada um dos cidadãos. É dizer, uma democracia que se verifique na prática através dos mecanismos de participação popular, dos quais se assegure que a participação popular não seja apenas um ideal, mas uma efetiva influência dos cidadãos na formação do Estado que se deseja. É como diz Castoriadis (1989, p. 11):

O governo da maioria só se justifica se dermos igual valor, no terreno do contingente e do provável, aos doxai de indivíduos livres. Mas se a igualdade de valor das opiniões deixa de ser um 'princípio contraditor', uma espécie de dispositivo pseudotranscendental, então o trabalho permanente de instituir a sociedade deve ser o de tornar os indivíduos tais que razoavelmente se possa postular que todas as opiniões têm o mesmo peso no terreno político. ... Tais indivíduos só podem se formar numa paidéia democrática e por meio dela, paidéia que não cresce feito planta, mas que deve ser um dos principais objetos de preocupação política da sociedade.

Eis a ágora. Esse espaço, nem público nem privado, mas antes, precisamente público e privado, onde os problemas particulares se encontram e passam a significar alternativas coletivas. Mas é preciso estar atento para as condições necessárias a que efetivamente esses espaços sejam capazes de realizar a tarefa de tradução, qual seja, a tarefa de identificar, a partir das demandas individuais, os anseios coletivos. 


\section{O DIREITO DE LIBERDADE EM PHILIP PETIT E A PARTICIPAÇÃO POPULAR: PARA UMA EFETIVA DEMOCRACIA}

Do ponto de vista normativo já se teve oportunidade de registrar que a participação democrática foi assegurada constitucionalmente. Contudo, para que ela seja capaz, como espaço de construção política democrática, de permitir que todos contribuam para o processo de identificação, deliberação, construção e, finalmente, tradução das questões individuais em públicas, ainda quando isso pressuponha a elevação dos níveis de tensionamento social, é preciso estar diante de um indivíduo livre.

Essa liberdade, pressuposta para o processo de construção democrática, não é aquela apenas formalmente como assegurada na constituição, tampouco, hoje, se confunde apenas com a liberdade negativa afirmada quando da transição dos estados absolutistas para os estados de direito, mas aquela que reúna uma série de condições psicológicas, sociais e normativas, que assegure uma condição de efetiva liberdade do indivíduo para a formação da vontade coletiva.

Por sua vez, a vontade coletiva não se restringe às decisões finais, englobando os pressupostos das decisões, ou seja, tudo a que diz respeito a elas, daí porque Castoriadis, em sua narrativa sobre a polis grega e a criação da democracia, chama atenção especial para o tipo de liberdade requerida e pressuposta para que os espaços públicos de construção democrática alcancem o seu escopo.

Distingue, então, entre o 'formal' e o 'real' e aponta, neste último caso, para um conteúdo que garanta a todos a mesma liberdade de pronunciamento. Valem a pena transcrever brevemente suas palavras (CASTORIADIS, 2002, p. 311):

Essa mudança equivale a instituir a possibilidade - e a realidade - da liberdade de expressão, de pensamento, de exame e de questionamento sem limites. E essa criação estabelece o logos como circulação do discurso e do pensamento no seio da coletividade. Ela associa-se aos dois traços fundamentais do cidadão já mencionados: a isègoria, direito igual para todos de falar com toda a franqueza, e a parrhèsia, o compromisso que cada qual assume de pronunciar-se efetivamente com toda a liberdade, sempre que se trate de assuntos públicos.

Mas o autor (2002, p. 311) vai além e afirma que o traço distintivo para o alcance daquilo que se pode esperar com o retorno à ágora é a coragem, a responsabilidade e a vergonha daqueles que vão compor esses espaços públicos.

Para o objetivo do presente trabalho a questão relativa à responsabilidade interessa de modo particular. Nessa linha ela compõe, em Philip Petit, aspecto fundamental para a efetividade da liberdade.

\section{A liberdade individual como adequação para ser considerado responsável}

Já se ressaltou que a modernidade prometeu uma liberdade não verificada, no que se apontou a necessidade de um retorno à ágora, o espaço de construção pública a partir da provocação suscitadas pelos 
indivíduos. Contudo, para que esses espaços efetivamente sejam capazes de serem reconhecidos como espaços públicos de construção democrática e alimentem o sentimento de liberdade efetiva, e não meramente aparente, existem pressupostos que condicionam a sua verificação.

Esse desafio ganha novos contornos a partir da análise que Philip Petit lança sobre a liberdade através de sua "teoria da liberdade", não mais compreendida em Kant como a propriedade da razão de ser lei para si mesma, mas relacionando-a à liberdade de escolha.

Dois aspectos chamam a atenção de Petit (2007, p. xi): o tratamento conjunto que vem sendo emprestado à liberdade da vontade e à liberdade política, e a tradição republicana de entender a liberdade como não dominação a qual foi sendo, paulatinamente, substituída pela concepção liberal de liberdade como nãointerferência.

Partindo da premissa de que o homem transita em duas esferas: a numenal e a fenomenal, ou da racionalidade e da sensibilidade, respectivamente, Petit propõe alguns questionamentos em torno das possibilidades reais da liberdade de escolha.

Preliminarmente, contudo, indaga as conclusões lançadas por Kant de que a liberdade possa ser compreendida como a propriedade da razão de ser lei para si mesma. Segundo Kant a condição do homem em ter clareza sobre todas as causas e condições existentes em torno de dado problema, considerando uma razão ou racionalidade, poderia representar um apontamento em direção a uma única escolha, do que seria possível identificar um nexo natural de causalidade entre os fatos e as escolhas. Mas isso retiraria a possibilidade de responsabilidade e imputação (PETIT, 2007, p. xiii), pois se tudo é natural e obedece a uma lógica causal, não há espaço para a vontade.

Petit vai chamar a atenção, então, para a condição fenomenal do homem, que o possibilita transitar na esfera da sensibilidade e consequentemente torna possível a ideia de liberdade de escolha.

Iniciando sua abordagem através do reconhecimento de três domínios de liberdade: o da ação, o do selfe o da pessoa, Petit (2007, p. 91) afirma que o objetivo de uma teoria da liberdade consiste em identificar as realizações e habilidades em função dos quais os agentes estão adequados a serem considerados como responsáveis. Nesse sentido:

O primeiro nível representa a liberdade desempenhada pelo agente em uma ou outra ocasião; o segundo diz respeito à liberdade do que ser que está implícita na habilidade do agente para identificar-se com as coisas realizadas; e o terceiro se relaciona à liberdade das pessoas em desfrutar um status social que faz com que a ação seja realmente delas e não uma ação que seja provocada sob a pressão dos outros.

Sem embargo, o autor, após reconhecer a existência de três teorias a justificar a liberdade (uma primeira baseada na teoria da ação livre e, por extensão, do self livre e da pessoa livre; a teoria do controle volitiva que é uma teoria do self livre e, por extensão da ação livre e da pessoa livre e, finalmente, a teoria do controle discursivo que é a teoria da pessoa livre, e, por extensão, do self livre e da ação livre) afirma que somente a teoria do controle vol.10, no. 01, Rio de Janeiro, 2017.pp. 127-148 
discursivo é capaz de satisfatoriamente justificar a liberdade.

Por essa teoria a pessoa considerada livre é aquela que pode discursar e ter acesso ao discurso. Pressupõe, pois, que a pessoa tenha capacidade raciocinativa e relacional, além de uma condição de igualdade em relação aos participantes do discurso. É dizer: o agente pode ser diretamente responsabilizado por aquilo que fez (posse: se ação foi livre); se reconhece ou assume na condição de responsável (self: se ele consegue identificar sua assinatura); e não tem sua escolha totalmente determinada (pessoa) ${ }^{4}$.

Mas qual a importância em estabelecer-se uma teoria da liberdade a partir dessa leitura? Consiste em que as pessoas se comprometem com os outros seres humanos de uma maneira diferente, que envolve a atribuição espontânea da responsabilidade. A liberdade é concebida como uma propriedade dos seres humanos e das ações desempenhadas por eles e isso tem uma aplicação prática muito apropriada.

Nessa toada, o livre agenciamento é possível na medida em que caracterize um processo voluntário que conduz à ação, mas pressupõe que aquele a quem seja imposta uma obrigação tenha capacidade para desempenhá-la (PETIT, 2007, p. 17).

Petit (2007, p. 17) de modo cristalino precisa o que considera um sujeito livre: "Mais especificamente, o sujeito é livre, exatamente, na medida em que ele é capaz de ser considerado responsável pelo critério implícito na prática. Alguém é livre, eu diria, até o ponto em que estiver adequado para ser considerado responsável”. A liberdade, pois, está relacionada intimamente ao nível de assunção de responsabilidade da condução dos atos.

A fonte primária para que alguém seja considerado responsável consiste em apresentar-se como adequado a ser considerado responsável, e isso pressupõe, em Petit (2007, p. 20), outras três condições:

As pessoas devem ser consideradas adequadas desde a perspectiva anterior à escolha e não só depois dela; devem ser adequadas de uma maneira personalizada, para serem consideradas responsáveis e não só adequadas de acordo com os padrões sociais imperantes; e devem ser propriamente adequadas para serem consideradas responsáveis e não simplesmente adequadas para serem tratadas como se fossem adequadas para serem consideradas responsáveis.

A primeira condição, qual seja, o de que as pessoas, para serem consideradas adequadas a serem tidas como responsáveis, devem sê-lo numa perspectiva anterior à escolha, significa que, de antemão, elas devem ter consciência de que se reconhecem e são achadas responsáveis ante determinado evento. A segunda condição pressupõe que elas não sejam reputadas como responsáveis apenas em função de alguma convenção padronizada, é dizer: não é possível que essa adequação seja pressuposta, ou padronizada, é preciso que ela seja personalizada, verificada em face do agente que se requer adequado. Finalmente, a terceira condição pressupõe que a pessoa seja propriamente responsável e não simplesmente tratada como se fosse propriamente responsável (PETIT, 2007, p. 22-25), ou seja, é preciso que haja uma correspondência efetiva entre a adequação pessoal verificada e a

\footnotetext{
${ }^{4} \mathrm{O}$ primeiro olhar relativo à posse compreende a circunstância de que o fato é considerado adequado para responsabilizar alguém. $\mathrm{O}$ self significa a capacidade de o agente ter consciência em relação a ação, ou seja, refletir sobre os pensamentos que o levaram a vol.10, no. 01, Rio de Janeiro, 2017.pp. 127-148
} 
responsabilidade.

Estabelecidas as condições necessárias a que alguém possa ser considerado livre, ou seja, liberdade enquanto adequação para ser considerado responsável, Petit vai além para estabelecer sua teoria de liberdade como controle discursivo.

\section{A liberdade como controle discursivo}

A teoria da liberdade como controle discursivo centra-se precipuamente na condição da liberdade da "pessoa", e menos na liberdade do "self" ou de "ação". Significa que o ponto nodal dessa teoria reside na condição em que a liberdade de escolha não se dê de forma coagida, pressionada ou ameaçada e que, ao mesmo tempo, sejam asseguradas aos indivíduos opções que lhes garantam a possibilidade de escolha (PETIT, 2007, p. 92).

Há, pois, certa preocupação em torno da qualidade dos relacionamentos estabelecidos entre as pessoas para o fim de verificar se efetivamente essas últimas podem ser consideradas adequadas como responsáveis, ou se não haveria situações nas quais a posição entre elas obstrui a possibilidade de escolhas.

Usualmente o relacionamento entre as pessoas, especialmente no tocante ao enfrentamento de problemas comuns, ocorre por meio do discurso que, nada mais é, que um processo de interação que se orienta por processos de revezamento entre as pessoas na tentativa de resolverem um problema.

Nessa linha Petit (2007, p. 96) chama a atenção para a necessidade de que as interações discursivas se deem de forma discursivo-amigáveis, ou seja, que os relacionamentos não sejam capazes de, ainda que em certa medida, estabelecerem obstáculos, perigos ou restrições às influências discursivas entre as partes e não levantem os custos para alcançá-las.

Afirmando a importância desses relacionamentos discursivo-amigáveis, Petit (2007, p. 97) os considera mecanismos de preservação da liberdade das pessoas:

A afirmação de que os relacionamentos discursivo-amigáveis preservam a liberdade das pessoas como tal, não é uma observação casual sobre um feliz acidente da vida humana e social. Nós concebemos a nós mesmos e uns aos outros não somente como meros sistemas intencionais com crenças e desejos, mas como sujeitos que podem conduzir um discurso com o outro ou consigo mesmo, na tentativa de dar forma às nossas crenças e desejos e naturalmente esse auto concepção tem implicações importantes nas atitudes para relacionamentos discursivo-amigáveis.

Naturalmente que o reconhecimento da importância e do indivíduo em sentir-se parte desse processo de construção discursiva não ensejará qualquer entrave a que o indivíduo se considere e seja considerado adequado como responsável pelo que decide e faz. Por isso, as interações discursivo-amigáveis, ou o controle discursivo, pressupõe uma capacidade relacional e outra raciocinativa, e se aperfeiçoam mediante o seu exercício (PETIT, 2007, p. 100). 
Mas, se por um lado a liberdade como controle discursivo pressupõe esse dual apresentado, de outro ela estará comprometida na medida em que a capacidade seja constrangida por mecanismos de controle discursivo não-amigáveis, a exemplo da coerção hostil ou das condições de submissão de vontade, ou seja, formas de interferência que afetam a integridade em relação aos interesses assumidos.

Eis o desafio da teoria do controle discursivo: assegurar o não comprometimento das escolhas, sob uma perspectiva social e psicológica, no desenvolvimento do discurso. Corrobora esse compromisso a proibição de todas as formas de intervenções dos indivíduos que, de qualquer modo, restrinjam, desgastem ou coloquem em perigo o discurso (PETIT, 2007, p. 102) pois, em última análise, eles diminuem, em alguma medida, a adequação do agente para ser considerado responsável.

\section{Liberdade como ideal de construção política}

A análise da liberdade à luz da politização põe em questão indagações sobre que liberdade deve ser assegurada pelo Estado, na medida em que se afigura como sujeito coletivo, politicamente organizado, detentor do uso da força, e sendo a concretização da liberdade como um ideal político pressuposto de sua própria formação.

A preocupação estatal com o exercício efetivo da liberdade está diretamente relacionada ao aumento da liberdade dos indivíduos envolvidos e que compõe a sociedade. Petit (2007, p. 175) afirma que a orientar-se por essa perspectiva "o Estado deve se interessar pelo controle discursivo das coletividades, só se restringindo ao interesse que esteja associado a um nível correspondente de controle discursivo por parte dos indivíduos envolvidos". De fato, o contrário poderia representar agenciamento invasor ou uma manipulação opressiva.

Não se descura, contudo, que a ausência da preocupação estatal na consecução do ideal de liberdade política significa, a exemplo do que já se mencionou, em apropriação desses espaços pelo próprio mercado. A questão, então, remete à identificação do objeto de sua preocupação quando se relacione com um ideal de liberdade que não suponha apenas sua simples retirada desse espaço jurídica e socialmente relevante.

Seu objeto, por relacionar-se à liberdade individual, pressupõe o estar atento a que a liberdade individual, especialmente, nos espaços de construção coletiva se opere, assegurando que as condições pressupostas de retorno à ágora se desenvolvam de modo a que cada indivíduo assuma a condição de adequação para ser considerado responsável na tradução das demandas coletivas identificadas a partir das individuais suscitadas.

Isso passa necessariamente com a asseguração de condições de oportunidades adequadas pelos indivíduos, ou seja, pela verificação das condições de escolhas, que certifique que as escolhas não são subdeterminadas por condições adversas que as transformem em mera formalidade. Mas também passa, segundo Petit (2007, p. 176) pela percepção das pré-condições interpessoais, sendo tanto mais libertador quanto recaia 
sobre essa dupla análise 5 .

Portanto, não é de estranhar que a liberdade política que deva ser assegurada pelo Estado pressuponha um olhar sobre as questões relacionadas às demandas interpessoais, no que apontará para as condições do ambiente em que se desenvolverá o controle discursivo, mas também deverá voltar sua atenção para as relações intrapessoais, correspondentes às oportunidades determinadas impessoalmente em face dos indivíduos.

De modo mais profundo que o proposto tradicionalmente a partir do conceito de liberdade positiva e negativa, Petit (2007, p. 177) identifica três condições que podem ser traduzidas do ideal de liberdade política: a liberdade política como não-limitação; a liberdade política como não-interferência e a liberdade política como não-dominação.

A liberdade política como não-limitação consiste em que todas as limitações ou inibições de caráter impessoal ou interpessoais estejam ausentes. Contudo, por fazer referência a limitações intencionais ou quase intencionais, ela não atende plenamente às condições necessárias de liberdade política como controle discursivo.

Com a acepção da liberdade política como não-interferência também não é diferente. Sendo encarada como forma única de inibição interpessoal na liberdade, supõe que a liberdade se realize exclusivamente mediante a redução ou eliminação da interferência. Nesse viés, a interferência consiste na piora das escolhas por meio de uma das seguintes iniciativas: a remoção de alguma delas; o aumento dos custos relativos à dada opção; ou no negar conhecimento a outras opções disponíveis ou de seus custos associados ${ }^{6}$.

Por outro lado, importante destacar a crítica de Petit (2007, p. 188) no sentido de que é preciso distinguir as hipóteses em que a interferência, no caso do Estado, seja legítima e, por isso, não arbitrária, das hipóteses em que a interferência do Estado assuma a condição de poder relativamente arbitrário. O primeiro caso,

\footnotetext{
${ }^{5}$ Vale a pena transcrever a indagação e a resposta em torno da qual Petit (2007, p. 176) se posiciona sobre isso: "Diríamos que o Estado deveria se preocupar com os requerimentos interpessoais, mas não com os requerimentos intrapessoais do controle discursivo entre os indivíduos que são seus membros? Um terceiro problema sugere que isso também não é correto. Os requerimentos mencionados, todos eles, envolvem mais o agenciamento do que o ambiente no qual o agenciamento opera. Isso é compreensível, dado que até este ponto do livro nós nos temos abstraído do ambiente. Porém, está claro que o Estado pode, utilmente, se preocupar tanto com o ambiente, quanto com o agenciamento. Ele pode tentar mitigar os efeitos de uma ordem natural desagradável ou de um sistema social desagradável e assegurar que as pessoas gozem de oportunidades adequadas, a respeito das quais elas possam fazer escolhas discursivamente controladas. Sendo assim, o ideal político de liberdade deveria refletir tal possibilidade e manter uma perspectiva favorável da ação, tanto no que se refere ao ambiente, quanto ao agenciamento.

${ }^{6}$ Pedimos vênia para transcrever trecho bastante elucidativo no qual Petit afirma que "o ideal de liberdade como não-interferência terá dois componentes, se ele está designado não somente para demonizar a interferência interpessoal, mas também para tratar limitações impessoais como um mal secundário. Ele sustentará que uma pessoa é politicamente livre só na medida em que, primeiro, ela não está sujeita à interferência por parte dos outros e, segundo, ela não está sujeita a limitações no gozo de tal nãointerferência. Na medida em que uma pessoa satisfaça o primeiro requerimento, ela gozará da liberdade formal como nãointerferência. Na medida em que uma pessoa satisfaça o primeiro requerimento, ela gozará da liberdade formal como nãointerferência. Na medida em que ela também satisfaça o segundo requerimento, gozará da liberdade efetiva ou real como nãointerferência (Van Parijs, 1995). A liberdade formal como não-interferência requer a ausência do fato - interferência - que compromete, inerentemente, tal liberdade. A liberdade de fatores não comprometedores - digamos, obstáculos naturais - que condicionam até que ponto as pessoas podem fazer escolhas bem-sucedidas; isto requer não somente uma capacidade para agir, vol.10, nº. 01, Rio de Janeiro, 2017.pp. 127-148 
por exemplo, poderá ser identificado quando o Estado atue ou interfere de modo a garantir a rastreabilidade dos interesses assumidos pelo indivíduo ou quando atua na ampliação das possibilidades postas à disposição dos indivíduos, de modo impessoal, visando ao melhoramento do gozo do controle discursivo pelas pessoas.

Trata-se, pois, de uma posição constitucionalmente empobrecida, a interpretação lançada sem qualquer refinamento de que a interferência em si seja o maior dos males à liberdade política.

O segundo problema que Petit chama a atenção e que guarda bastante pertinência com o tipo de liberdade que assegura uma efetiva participação dos indivíduos, especialmente, em vista da valorização das participações democráticas que uma sociedade complexa reclama, consiste na constatação de que, por vezes, a interferência, não obstante não seja estatal, é formulada por outros atores, de um modo bastante sutil, que sequer pode ser enquadrada como tal. Sem embargo, ela é efetiva no sentido de conduzir os indivíduos em direção aos resultados que deles se espera e que atua exclusivamente em vista de interesses bem particulares.

Isso é especialmente verificável quando se está diante de audiências públicas, ocasiões em que, normalmente, é perceptível o nível de defesa em torno dos interessados pelo empreendimento, ou mesmo, antes de suas realizações, mas já em vista delas, nos processos de aproximação ou cooptação dos indivíduos que compõe a comunidade diretamente afetada.

Nesse ponto, a compreensão de que o Estado deva assumir uma condição ou postura de não interferência representa uma perspectiva sociologicamente pobre diante do que dele se poderia esperar. Está-se, na verdade, diante de uma situação de dominação; ou seja, de apropriação do mercado, que, de forma sub-reptícia, é capaz de orientar toda uma comunidade em direção à aprovação do empreendimento que, não fosse a manipulação social, poderia ter outra conclusão.

Esse comportamento de retração estatal é o que infelizmente tem permeado as posturas do Estado nas sociedades modernas, e tem sido uma das grandes causas do enfraquecimento dos indivíduos em torno das questões coletivas.

Retornando os olhos para as manifestações de 2013, tem-se que, não obstante elas guardem um caráter simbólico de envolvimento dos indivíduos no tocante às questões públicas, na verdade, sua força é realmente e no máximo, simbólica. Seus laços são muito fluidos e efêmeros, incapazes de compor discursos politicamente organizados, e consequentemente de encaminhar uma agenda política.

Daí porque Nogueira (2013, p. 52) apresenta um prognóstico, em certo sentido, desanimador:

É impossível saber se as ruas continuarão mobilizadas, mas pode-se dizer que elas não têm como ir muito longe ou como impor mudanças substantivas, que mexam na estrutura da sociedade, que é onde estão a determinação e a raiz dos problemas. Têm baixo poder de agenda: não se entendem sobre as razões que as ativaram nem sobre os passos políticos que

sem interferência, mas também, um ambiente de oportunidades no qual exista um amplo escopo para o exercício dessa capacidade (Petit, 1997a, capítulo 2)”. 
terão de ser dados. Como a dimensão estrutural dos problemas não sofrerá alteração, ao menos no curto prazo, pode-se dizer que a instabilidade política e a revolta das ruas persistirão, assim como sua dificuldade de protagonizar situação de maior subjetividade política.

Em função de toda essa conjuntura, especialmente verificada em países periféricos, é que se concorda com Petit (2007, p. 190) quando defende que o ideal de liberdade política esteja relacionado ao ideal de nãodominação. Este coincide, em certa medida com o ideal de não-interferência, especialmente em relação às posturas estatais quando relacionadas às interferências relativamente arbitrárias, mas vai além. Exige também que os indivíduos estejam livres de um poder arbitrário de interferência por parte de outros indivíduos ou agências (PETIT, 2007, p. 191). É dizer: trabalha na criação de um ambiente tal que não exponha seus partícipes a situações de exposição a um poder de interferência arbitrária, seja esse poder exercido ou não.

Nesse trilho, o Estado deve ser capaz de direcionar ações, assumindo a condição de interferir proativamente, de modo a retificar situações de dominação que comprometam a liberdade. É preciso que se diga que essa interferência é não-arbitrária e, antes, legítima e necessária à manifestação do ideal de liberdade política necessário ao retorno à ágora.

Finalmente, o ideal de não-dominação não desconsidera, antes reconhece, situações que condicionam a liberdade de seus indivíduos e acabam por reduzir seu âmbito de liberdade. Nesse viés, para além de combater situações de agenciamento, trabalha também na criação de um ambiente que ofereça o mínimo de obstáculos naturais e sociais.

Assim agindo, o Estado atua em uma perspectiva constitucional e sociologicamente rica possibilitando a que os indivíduos, no âmbito do controle discursivo e no exercício do ideal de liberdade política, efetivamente assumam a condição de protagonistas, dialogando permanentemente em torno do projeto político cujas bases estão fixadas na Carta Constitucional (PETIT, 2007, p. 192-195).

\section{CONCLUSÃO}

Conclui-se, pois, que a identificação de horizontes mais promissores que aqueles que se podem vislumbrar através da democracia representativa passa pelo retorno à ágora: espaços nem públicos nem privados, antes públicos e privados, de construção de soluções coletivas em face de problemas individuais, mas que exigem níveis de liberdades individuais bem peculiares.

O cidadão, nessa toada, assume a condição de absoluto soberano que exercerá sua autonomia contribuindo coletivamente para o ideal de construção política que se deseja.

No caso da sociedade brasileira, o acirramento da crise política ao longo do tempo, situação que culminou com as manifestações sociais nas ruas, e em todo o território nacional, em 2013 e 2014, bem demonstra a necessidade desse retorno, por meio da implementação de condições que assegurem sua participação de modo 
mais efetivo na construção do projeto político de sociedade que se deseja, evidenciada à luz do esvaziamento do público a partir de projetos de governo que se afirmaram, antes, como de poder.

A sociedade brasileira parece ter despertado para sua situação de completa antiliberdade, reverberando a crise estatal em prover e dar respostas às suas demandas coletivas sentidas especialmente em relação às deficiências do sistema educacional, do sistema de saúde pública, dos transportes, da infraestrutura, da ineficiência dos governos e dos sistemas políticos, com suas taxas absurdas de corrupção.

A chave para isso pressupõe a igualdade de valor na participação de cada um dos cidadãos. É dizer, através da construção de uma democracia que se verifique na prática mediante a asseguração de que a participação popular não seja apenas um ideal, mas uma efetiva influência dos cidadãos. Nesse sentido, é seu pressuposto a liberdade desses cidadãos.

Essa liberdade, pressuposta para o processo de construção democrática, não é aquela apenas formalmente como assegurada na constituição, tampouco, hoje, se confunde apenas com a liberdade negativa afirmada quando da transição dos estados absolutistas para os estados de direito, mas aquela que reúna uma série de condições psicológicas, sociais e normativas, que compõe uma condição de efetiva liberdade do indivíduo para a formação da vontade coletiva.

Daí porque a contribuição de Phillip Petit é interessante na medida em que, sua teoria de liberdade, pressupõe a reunião de condições que sejam capazes de afirmar o indivíduo como adequado para ser considerado responsável. A partir dessa premissa é possível falar na liberdade como controle discursivo, como mecanismo necessário a que a construção coletiva se desenvolva, é dizer: a partir de condições que assegurem que os indivíduos não terão suas escolhas comprometidas, seja numa perspectiva social, seja numa perspectiva psicológica.

O papel do Estado deverá ser o de direcionar ações, assumindo a condição de interferir proativamente, de modo a retificar situações de dominação que comprometam essa concepção de liberdade. Nesse viés, a interferência não se confunde com arbitrariedade ou agenciamento, apresentando-se, antes, como legítima e necessária à manifestação do ideal de liberdade política necessário ao retorno à ágora.

Essa parece ser a perspectiva constitucional e sociologicamente rica, qual seja, a que possibilita aos indivíduos, no âmbito do controle discursivo e no exercício do ideal de liberdade política, que efetivamente assumam a condição de protagonistas, dialogando permanentemente em torno do projeto político cujas bases estão fixadas na Carta Constitucional. 


\title{
PARTICIPATORY DEMOCRACY IN THE LIGHT OF THE 1988 CONSTITUTION: FOR A CONNECTION BETWEEN PHILIP PETIT'S RIGHT TO FREEDOM AND ZIGMUND BAUMAN RETURN OF THE AGORA
}

\begin{abstract}
The 2013 street protests and the realization regarding the lack of power by the general public, while seemingly contradictory, encompass the complementarity relation that seems to be the hallmark of modern societies. In this article we analyze the alternative of returning to the agora, a space which is not public nor private, but public and private, where collective solutions are developed to address individual problems, treated by Zigmund Bauman, and the constant demands of Philip Petit's theory regarding liberty, which is seen as condition for one to be considered responsible, aiming at offering a more promising horizon to be trodden by contemporary society. In the face of the nature of the proposed objectives and the authors referred in the analytic process the dialectic approach was used. By combining the two aforementioned aspects, we envisage a rich constitutional and sociological perspective, one that allows the individuals, in the scope of discursive control and the exercise of political freedom, to effectively assume the condition of protagonists, dialoguing permanently with the political project whose bases are fixed in the Constitution.
\end{abstract}

Keywords: Democracy; Political Freedom; Responsability; Popular Participation.

\section{REFERÊNCIAS BIBLIOGRÁFICAS}

ACKERMAN, Bruce. Tradução: Mauro Raposo de Mello. Nós o povo soberano. Belo Horizonte: 2006.

BAUMAN, Zigmund; tradução, Marcus Penchel. Em busca da política. Rio de Janeiro: Jorge Zahar ed., 1999.

BOURDIER, Pierre. O Poder Simbólico. Rio de Janeiro: Bertrand Brasil, 1989.

BRASIL, Constituição (1988). Constituição da República Federativa do Brasil. Brasília, DF: Senado, 1988.

CASTORIADIS, Cornelius. Democracy as procedure and democracy as regime. Constellations, 1/1997.

As encruzilhadas do labirinto II: os domínios do homem. 2 ed. Paz e Terra. Rio de Janeiro: 2002, v. 2.

DANNER, Leno Francisco. Habermas e a ideia de continuidade reflexiva do projeto de Estado de bem-estar social. São Paulo: Analise Social, 2013.

HABERMAS, Juergen. A nova intransparência. A crise do Estado do bem-estar social e o esgotamento das energias utópicas. São Paulo: Cebrap, 1987.

HESSE, Konrad. Temas Fundamentais do Direito Constitucional/Konrad Hesse; textos selecionados e traduzidos por Carlos dos Santos Almeida, Gilmar Ferreira Mendes, Inocêncio Mártires Coelho. São Paulo: Saraiva, 2009.

NOGUEIRA, Marco Aurélio. As ruas e a democracia - ensaios sobre o Brasil contemporâneo. Rio de Janeiro: 2013. 
PETIT, Philip. Teoria da liberdade. Belo Horizonte: Del Rey, 2007.

SOUZA, Jesse. A construção social da subcidadania: para uma sociologia política da modernidade periférica. Rio de Janeiro: Iuperj, 2006.

Trabalho enviado em 13 de abril de 2016.

Aceito em 20 de setembro de 2016. 